Document downloaded from:

http://hdl.handle.net/10251/52209

This paper must be cited as:

Meseguer-Lloret, S.; Torres-Cartas, S.; Gómez Benito, C. (2010). Flow injection photoinduced chemiluminescence determination of imazalil in water samples. Analytical and Bioanalytical Chemistry. 398(7-8):3175-3182. doi:10.1007/s00216-010-4227-1.

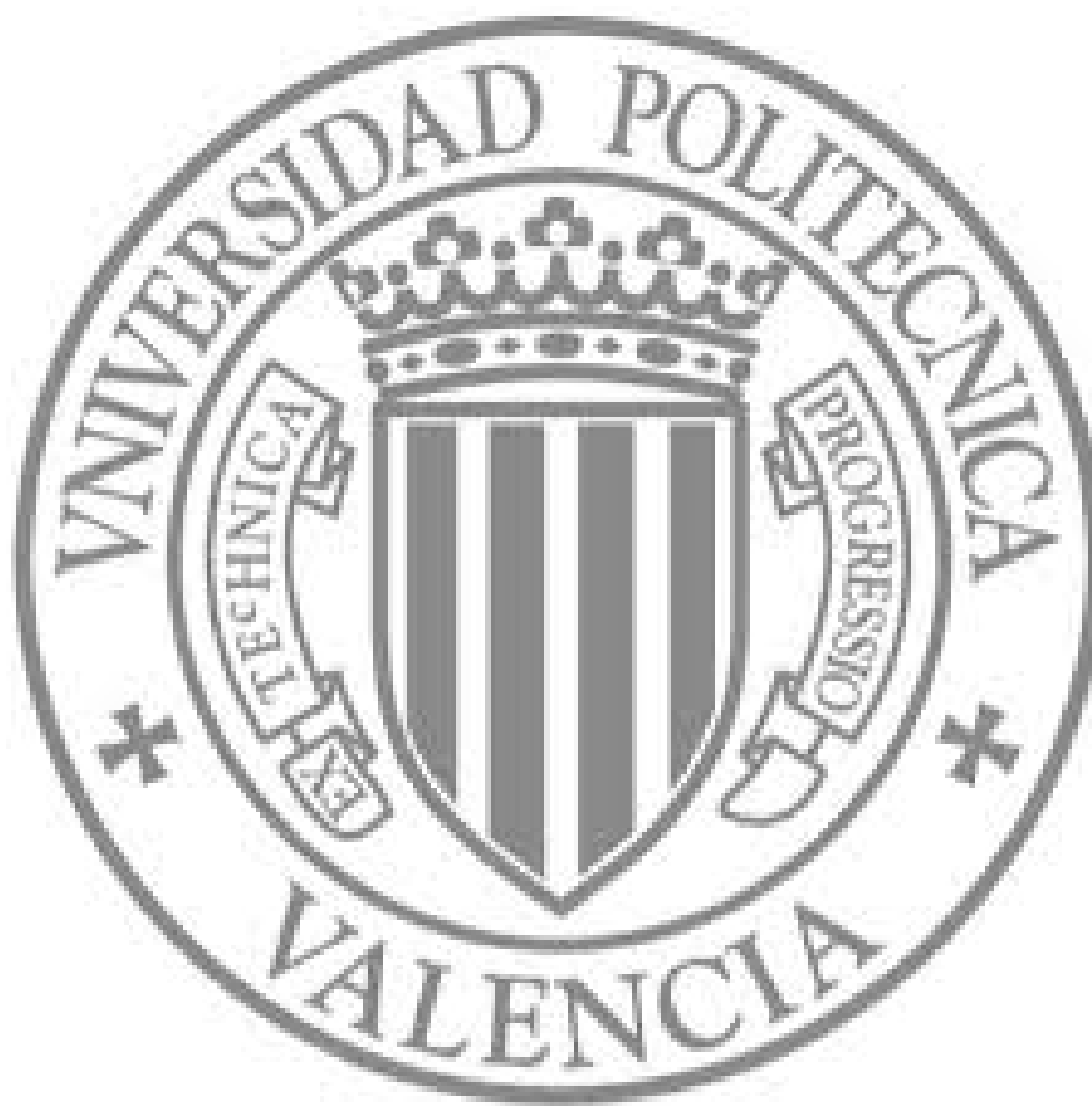

The final publication is available at

http://dx.doi.org/10.1007/s00216-010-4227-1

Copyright Springer Verlag (Germany) 


\title{
Flow injection photoinduced chemiluminescence determination of Imazalil in water samples
}

\author{
S. Meseguer-Lloret* ${ }^{*}$ S. Torres-Cartas and M.C. Gómez-Benito
}

Integrated Coastal Management Research Institute, Higher Polytechnic School of Gandia, Polytechnic University of Valencia, Calle Paranimf 1, 46730 Grau de Gandia, Gandia, Valencia, Spain

* Corresponding author: e-mail address: sumello@qim.upv.es

Telephone number: 0034962849333 Fax number: 0034962849309

\section{Abstract}

In this work, a fast, simple and economic method is proposed for the determination of Imazalil in water samples by flow injection photoinduced chemiluminescence. Imazalil degrades in basic media by means of a photoreactor and the resulting photofragments react with ferricyanide and generate the direct chemiluminescence signal. To the authors' knowledge this is the first time a chemiluminescence method is proposed for the determination of this fungicide. In the experimental setting, all physical and chemical parameters in the flow injection chemiluminescence system were optimized. In the absence of preconcentration, the linear dynamic range for Imazalil was $0.75-5 \mathrm{mg} \mathrm{L}^{-1}$ and the detection limit was $0,171 \mathrm{mg} \mathrm{L}^{-1}$. The application of solid phase extraction with C18 cartridges allowed the elimination of interference ions and the reduction of the linear dynamic range to $15-100 \mathrm{~g} \mathrm{~L} \mathrm{~L}^{-1}$, being the detection limit $3.4 \mu \mathrm{g} \mathrm{L}^{-1}$. This detection limit is below the maximum concentration level established by the Regulations of the Hydraulic Public Domain for pesticide dumping. The sample throughput after solid phase extraction of the analyte was 12 samples hour ${ }^{-1}$. Intraday and interday coefficients of variation were below $9.9 \%$ in all cases. This method was applied to the analysis of environmental water samples, obtaining recoveries between 95.7 and $110 \%$.

Keywords: Imazalil, chemiluminescence, flow injection, solid phase extraction, water 


\section{Introduction}

Imazalil ((RS)-1-( $\beta$-allyloxy-2,4-dichlorophenylethyl)imidazole) is one of the most employed post-harvest fungicides for citric fruits. Post-harvest fungicides are usual in preservation and storage of citric fruits at low temperatures. Imazalil is employed on fruit, vegetables and ornamentals in the control of a wide range of fungi such as Tilletia and Helminthosporium spp. Nowadays, according to the Phytosanitary data base of the Spanish Ministry of Environment and Rural and Marine, 23 formulations of fungicides that contain Imazalil in the range of $0.02 \%$ to $50 \%$ are regularly used in Spain in the preservation of fruits like pears, oranges, apples, and so on. European legislation on the quality of water intended for human consumption [1] establishes the recommended maximum limit for total pesticides in $0.5 \mu \mathrm{g} \mathrm{L}^{-1}$. On the other hand, the maximum concentration level established by the Regulations of the Hydraulic Public Domain for pesticide dumping is $50 \mu \mathrm{L} \mathrm{L}^{-1}$ [2]. Therefore, due to its toxic nature for human health and environment, analytical methods to detect and quantify Imazalil in environmental samples are required.

The most employed methods for Imazalil determination are based on separation techniques such as HPLC coupled to mass detection [3-5] or UV detection [6-8]. The great majority of these methods have been successfully applied to the separation and quantification of a large number of pesticides in citric fruits and vegetables. However, almost all of them gave poor recoveries specifically for Imazalil. Gas chromatography coupled to mass detection [9] and micellar electrokinetic chromatography with diode array detection [10] were applied and Imazalil recoveries were also poor (51-81\% and 48-58\% respectively). These poor recoveries were due to the complex extraction procedures applied to these kinds of samples (citric fruits or vegetables). Although all of these analytical methods have very good sensitivity and selectivity, their main drawbacks are the time-consumption and the need of complex instrumentation.

On the other hand, the development of analytical procedures to evaluate residues of Imazalil fungicide in water samples is interesting in order to regulate its dumping. In this sense, only three references $[4,11,12]$ have been found in which Imazalil was studied in water samples. The first reference [4] is a very sensitive method for screening a wide range of organic pollutants in water 
samples, but no quantification results were described. The second one [11] describes the bioautograph technique for multiresidue determination of fungicide residues in plants and water, but Imazalil has only been studied in crop samples. Finally, in [12] a method based on DI-SPME and GC-MS for the determination of pesticides in surface and groundwater samples was described. In this last reference, analytical results for Imazalil were good, but the method required complex instrumentation.

We propose a simple, rapid and sensitive method consisting of the direct flow injection photoinduced chemiluminescence of Imazalil. Chemiluminescence $(\mathrm{CL})$ detection provides attractive methods for trace analysis due to its high sensitivity, wide dynamic concentration range, fast kinetics and low cost. This technique, combined with flow injection systems, provides high sampling rates with good interday and intraday precision. To this end, flow injection chemiluminescence ( $\mathrm{FI}-\mathrm{CL}$ ) methods have been developed in order to analyze herbicides [13, 14], metal ions [15-17] and pharmaceuticals [18, 19] among others. In some cases, solid phase extraction of the analytes has been carried out in order to remove interferences and preconcentrate the sample [13]. Moreover, the photodegradation of the analyte can improve the chemiluminescence signal due to the formation of new fragments that increase chemiluminescence emission. In fact, flow injection photoinduced chemiluminescence has been recently used in the determination of sulphonamides [20], thiazides [21], pharmaceuticals [22, 23] and pesticides [24, 25] providing highly sensitive methods.

In this work, the chemiluminescence signal was generated by the reaction between photodegraded Imazalil and ferricianyde in a basic medium. All physical and chemical parameters of the FI-CL system were optimized in order to obtain high sensitivity and selectivity. The method was satisfactorily applied to the analysis of Imazalil in environmental water samples after solid phase extraction. To the authors' knowledge no chemiluminescence method has been reported for the determination of fungicide Imazalil. 


\section{Experimental}

\subsection{Reagents and solutions}

All solutions were prepared in Milli-Q water (Millipore, Bedford, MA, USA) and all reagents were of analytical grade.

The following chemical reagents were used: $\mathrm{Ce}\left(\mathrm{SO}_{4}\right)_{2} \cdot 4 \mathrm{H}_{2} \mathrm{O}, \mathrm{KIO}_{4}, \mathrm{H}_{3} \mathrm{BO}_{3}$, $\mathrm{NH}_{4} \mathrm{Cl}, \mathrm{KI}$, and $\mathrm{CH}_{3} \mathrm{COONa} \cdot 3 \mathrm{H}_{2} \mathrm{O}$ were purchased from Scharlau (Barcelona, Spain); $\mathrm{KMnO}_{4}, \mathrm{~K}_{3}\left(\mathrm{Fe}(\mathrm{CN})_{6}\right), \mathrm{K}_{2} \mathrm{~S}_{2} \mathrm{O}_{8}, \mathrm{NaH}_{2} \mathrm{PO}_{4} \cdot 2 \mathrm{H}_{2} \mathrm{O}$, Glycine, $\mathrm{NaCl}, \mathrm{K}_{2} \mathrm{SO}_{4}$, $\mathrm{NaOH}, \mathrm{Na}_{2} \mathrm{CO}_{3} \cdot 10 \mathrm{H}_{2} \mathrm{O}$ and Triton X-100 from Panreac (Barcelona, Spain); $\mathrm{H}_{2} \mathrm{SO}_{4} 96 \%, \mathrm{H}_{2} \mathrm{O}_{2} 36 \%$, ethanol and acetonitrile from Merck (Darmstadt, Germany); sodium dodecyl sulphate (SDS) from Fluka (Steinheim, Germany); and acetone, dichloromethane and methanol were from J.T.Baker (Deventer, Holland).

Cations tested as potencial inorganic interferents were prepared from chlorides $\left(\mathrm{Ca}^{2+}, \mathrm{Cr}^{3+}, \mathrm{Pb}^{2+}, \mathrm{Na}^{+}, \mathrm{Mg}^{2+}, \mathrm{Cd}^{2+}\right.$ and $\mathrm{K}^{+}$(Panreac) and $\mathrm{NH}_{4}^{+}, \mathrm{Co}^{2+}, \mathrm{Ni}^{2+}, \mathrm{Mn}^{2+}$, $\mathrm{Fe}^{3+}($ Scharlau $\left.)\right)$ or from sulphates $\left(\mathrm{Fe}^{2+}, \mathrm{Zn}^{2+}\right.$ and $\mathrm{Cu}^{2+}$ (Panreac)). Sodium anions such as nitrite and nitrate from Probus (Badalona, Spain) and chromate from Scharlau were also tested.

Potential organic interferents such as imidazolidinethione, myclobutanyl, thiabendazole and triflumizole were purchased from Riedel de Haën (Seelze, Germany).

The following reagents were used as sensitizers: eosyn $Y$ (Panreac), rhodamin B (Merck), fluorescein and formic acid (Scharlau), $\beta$-ciclodextrin (Fluka), riboflavin and quinine hydroclhoride (Sigma, St. Louis, MO).

Imazalil (99.8\%, Riedel de Haën, Seelze, Germany) stock standard solution of $100 \mathrm{mg} \mathrm{L}^{-1}$ was prepared by dissolving the pure compound in water. The solution was sonicated in an ultrasonic bath (J.P. Selecta, Barcelona, Spain) for 15 minutes and stored in the dark at $4^{\circ} \mathrm{C}$. Working Imazalil solutions were prepared by diluting the stock standard solution in water. 


\subsection{Apparatus}

The flow injection chemiluminescence manifold (Figure 1) consists on a Gilson Minipuls peristaltic pump (Wothington, OH, USA) furnished with polyvinyl chloride pumping tubes (Omnifit, Cambridge, UK). The flow system was designed with PTFE coil of $0.8 \mathrm{~mm}$ i.d., a Rheodyne 5041 injection valve (Cotati, CA, USA) equipped with a loop of $950 \mu \mathrm{L}(0.8 \mathrm{~mm}$ i.d.) and a water bath (J.P. Selecta) used to heat the sample loop and the carrier reactor of $1.156 \mathrm{~mL}$ (coil of $0.8 \mathrm{~mm}$ i.d.) inserted in the carrier stream. The photoreactor consisted of a $400 \mathrm{~cm}$ length and $0.8 \mathrm{~mm}$ i.d. PTFE tubing helically coiled around a $15 \mathrm{~W}$ lowpressuremercury lamp (Sylvania, Madrid, Spain) for germicidal use. The flow cell was a flat-spiral glass tube of $1 \mathrm{~mm}$ i.d. and $3 \mathrm{~cm}$ total diameter backed by a mirror for maximum light collection. The photodetector package was a P30CWAD5 type 9125B photomultiplier tube supplied by Electron Tubes (Uxbridge, United Kingdom); it was located in a laboratory-made light-tight box. The output was fed to a computer equipped with a counter-timer, also supplied by Electron Tubes.

\subsection{Flow injection procedure}

All physical and chemical parameters of the FI-CL system were optimized in order to obtain the best sensitivity and selectivity for Imazalil determination. In the general FIA procedure (Figure 1), the standard or sample (S) prepared in $0.01 \mathrm{M}$ carbonate buffer $\mathrm{pH} 9.5$, flowed at $1 \mathrm{~mL} \mathrm{~min}^{-1}$ along the photoreactor $(\mathrm{Ph})$ and filled the sample loop $(\mathrm{L})$ of $950 \mu \mathrm{L}$. The loop was located on a water bath (WB) at $60^{\circ} \mathrm{C}$. The carrier stream (C), Milli-Q water, was heated in the water bath at $60^{\circ} \mathrm{C}$ by means of a reactor $(R)$ and flowed at $7.5 \mathrm{~mL} \mathrm{~min}^{-1}$. The oxidant stream (O), $0.5 \mathrm{mM}$ ferricyanide in $1.25 \mathrm{M} \mathrm{NaOH}$, flowed at $2.5 \mathrm{~mL} / \mathrm{min}$ and merged with the carrier stream just before the detection cell (D). 


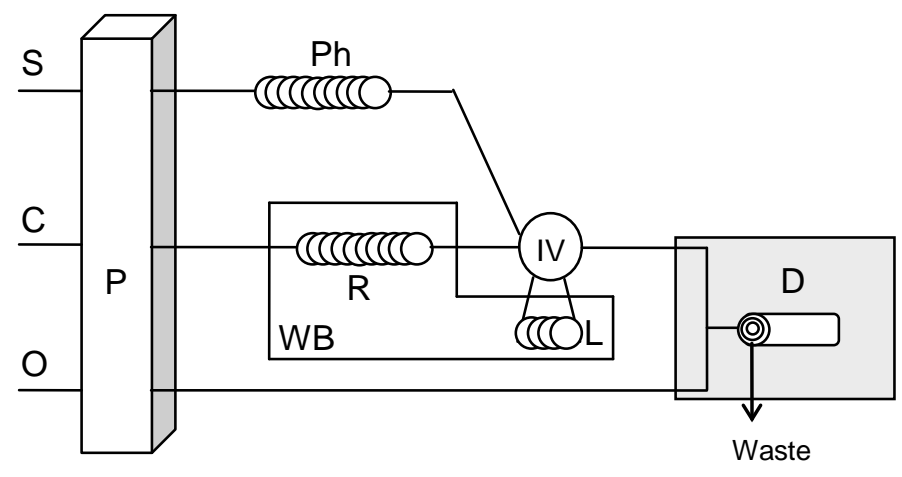

Figure 1: Flow injection chemiluminescence manifold. S: Sample stream: Imazalil prepared in $0.01 \mathrm{M}$ carbonate buffer $\mathrm{pH} 9.5$; C: Carrier stream: water; O: Oxidant stream: $0.5 \mathrm{mM} \mathrm{Fe}(\mathrm{CN})_{6}{ }^{3-}$ in $1.25 \mathrm{M}$ $\mathrm{NaOH}$; P: Peristaltic pump; Ph: Photoreactor; WB: Water bath $60^{\circ} \mathrm{C}$; R: Carrier reactor; L: Sample loop; IV: Injection valve; D: Chemiluminescence detector.

\subsection{Standard preparation}

Imazalil standard solutions were prepared in absence or in presence of ethanol. Standard solutions without ethanol were prepared containing $0.01 \mathrm{M}$ carbonate buffer pH 9.5 and variable amount of Imazalil stock standard solution. Standard solutions with ethanol were prepared containing $20 \%$ Ethanol, $0.01 \mathrm{M}$ carbonate buffer $\mathrm{pH} 9.5$ and variable amount of Imazalil stock standard solution.

\subsection{Solid phase extraction (SPE)}

Solid phase extraction was applied in order to avoid interferences from matrix components and to introduce a pre-concentration step.

SPE cartridges (Bond Elut C18 $0.5 \mathrm{mg}$ ) were conditioned by drawing with 5.0 $\mathrm{mL}$ of methanol followed by $2.5 \mathrm{~mL}$ of $0.05 \mathrm{M}$ carbonate buffer $(\mathrm{pH}$ 9.5). Then variable volumes of standard solution $(10-500 \mathrm{~mL})$ or $250 \mathrm{~mL}$ of water sample were transferred to the cartridge. In order to wash the cartridge, $1.5 \mathrm{~mL}$ of $0.1 \mathrm{M}$ hydrochloric acid and $1.5 \mathrm{~mL}$ of Milli-Q water were flushed. After that, the cartridge was dried under vacuum for 5 minutes and elution was performed by means of the addition of $2 \mathrm{~mL}$ of ethanol. The eluate was buffered by adding 0.2 
$\mathrm{mL}$ of $0.5 \mathrm{M}$ carbonate $\mathrm{pH} 9.5$, and finally it was diluted up to $10 \mathrm{~mL}$ with Milli-Q water prior to $\mathrm{FI}-\mathrm{CL}$ analysis.

\subsection{Sample preparation}

Water samples from different sources were analysed. They were named as follows: tap water (S1, S2, S3 and S4), mineral water (S5, S6), river water (S7) and well water (S8).

Samples were collected in plastic bottles, filtered under vacuum with polyamide membrane filters of $0.45 \mu \mathrm{m}$ and stored at $4^{\circ} \mathrm{C}$ in a refrigerator. Before applying SPE procedure, samples S1, S5, S7 and S8 were spiked with $0.06 \mathrm{mg} \mathrm{L}^{-1}$ of Imazalil in triplicate, and samples S2, S3, S4 and S6 were spiked at four Imazalil concentration levels (0.03, 0.06, 0.09 and $\left.0.16 \mathrm{mg} \mathrm{L}^{-1}\right)$.

\section{Results and discussion}

\subsection{Preliminary study of the FI system: Selection of the oxidation system and the photodegradation medium}

In order to obtain a direct chemiluminescence signal for Imazalil, different common oxidation systems were tested using the assembly described in Figure 1 and a standard of $10 \mathrm{mg} \mathrm{L}^{-1}$ of Imazalil. The oxidation systems studied were: $\mathrm{MnO}_{4}^{-}, \mathrm{Ce}(\mathrm{IV}), \mathrm{IO}_{4}^{-}$and $\mathrm{S}_{2} \mathrm{O}_{8}^{2-}$ in $2 \mathrm{M} \mathrm{H}_{2} \mathrm{SO}_{4}, \mathrm{H}_{2} \mathrm{O}_{2}$ in $2 \mathrm{M} \mathrm{NaOH}$ and $\mathrm{Fe}(\mathrm{CN})_{6}^{4-}$

in $1 \mathrm{M} \mathrm{NaOH}$. Each oxidation system was tested at different oxidant concentration levels (ranging from $1 \cdot 10^{-5} \mathrm{M}$ to $0.01 \mathrm{M}$ ) using three photodegradation media: water, $0.1 \mathrm{M} \mathrm{NaOH}$ and $0.1 \mathrm{M} \mathrm{H}_{2} \mathrm{SO}_{4}$. In this study, the water bath (Figure 1) was not used and the sample carrier stream was split into two channels in order to introduce Imazalil solution and photodegradation medium separately.

In this preliminary study, it was observed that no chemiluminescence signal appeared by using $\mathrm{IO}_{4}^{-}$and $\mathrm{S}_{2} \mathrm{O}_{8}^{2-}$ as oxidation systems. In contrast, the best chemiluminescence signals were obtained with oxidation systems such as ferricyanide or hydrogen peroxide with similar sensitivity. In order to ensure stability in the FI system, hydrogen peroxide was discarded due to the formation 
of bubbles, and finally $0.5 \mathrm{mM}$ ferrycianide prepared in $1 \mathrm{M} \mathrm{NaOH}$ was selected for the study of direct chemiluminescence of Imazalil.

With the selected oxidation system, the best chemiluminescence signal was obtained with $0.1 \mathrm{M} \mathrm{NaOH}$ as photodegradation medium.

\subsection{Optimization of chemical and physical parameters of the FI system}

In the optimization process, a $10 \mathrm{mg} \mathrm{L}^{-1}$ standard of Imazalil without ethanol was used (if not otherwise stated) and the standard channel (Figure 1) was divided into two sub-canals to introduce the photodegradation medium separately.

\subsubsection{Photodegradation medium}

Different common buffer solutions were used in the basic medium in order to select the best photodegradation conditions for Imazalil.

The buffer solutions studied were: $0.1 \mathrm{M} \mathrm{NaOH} \mathrm{pH} 11,0.2 \mathrm{M} \mathrm{NH}_{4}{ }^{+} / \mathrm{NH}_{3}$ at $\mathrm{pH}$ 10.5, 0.02 $\mathrm{M} \mathrm{H}_{3} \mathrm{BO}_{3} / \mathrm{H}_{2} \mathrm{BO}_{3}{ }^{-}$and $0.02 \mathrm{M} \mathrm{CO}_{3}{ }^{2-} / \mathrm{HCO}_{3}{ }^{-} \mathrm{pH} 9.5,0.1 \mathrm{M}$ Glycine $\mathrm{pH}$ 8.5 and $0.1 \mathrm{M} \mathrm{H}_{2} \mathrm{PO}_{4} / \mathrm{HPO}_{4}{ }^{2-} \mathrm{pH} 8$ and $\mathrm{pH}$ 7. In these tests, the best chemiluminescence signal was obtained by using $0.02 \mathrm{M} \mathrm{CO}_{3}{ }^{2-} / \mathrm{HCO}_{3}{ }^{-} \mathrm{pH} 9.5$ as photodegradation medium.

The $\mathrm{pH}$ of the selected buffer solution, $0.02 \mathrm{M} \mathrm{CO}_{3}{ }^{2-} / \mathrm{HCO}_{3}{ }^{-}$, was varied between 8 and 10.5. Chemiluminescence signal increased up to $\mathrm{pH} 9.5$ and remained stable until $\mathrm{pH} 10.5$. Finally, a photodegradation buffer of $0.02 \mathrm{M} \mathrm{CO}_{3}{ }^{2-} / \mathrm{HCO}_{3}{ }^{-}$ $\mathrm{pH} 9.5$ was selected as optimum.

\subsubsection{Effect of chemiluminescence enhancers and organized media}

The use of organized media or fluorescent compounds that provide indirect chemiluminescence has become more extensive as they produce an increase in the sensitivity of the reaction under consideration. In order to examine the possibility of sensitizing the chemiluminescence reaction between the photofragments of Imazalil and the ferricyanide in basic media, sensitizers and common organized media were tested, such as: 1.2\%SDS, 0.6\% Triton X-100, 20\% Acetonitrile, 20\% ethanol, $0.1 \mathrm{mM}$ Eosin Y, $0.1 \mathrm{mM}$ riboflavin, $0.1 \mathrm{mM}$ rhodamin B, $0.1 \mathrm{mM}$ fluorescein, 1.2\% $\beta$-cyclodextrin, $0.1 \mathrm{mM}$ quinine and 0.5\% formic acid. These compounds were inserted into the FI system by using 2 
different set-ups: in the first one, the sensitizer was inserted before the photodegradation of Imazalil. In the second one, it was inserted afterwards. When inserting the sensitizer before the photodegradation step, an increase in reaction sensitivity was found when using Triton $X-100$, Eosin $Y$, riboflavin or fluorescein, but all of them gave very large signals for the blank and unreproducible peaks for Imazalil. Consequently, the use of these sensitizers was rejected. On the other hand, when the sensitizer was inserted after the Imazalil photodegradation, none of the sensitizers significantly improved the chemiluminescence signal.

\subsubsection{Temperature of the FI-CL system}

The temperature of the FI-CL system was controlled between $22-81^{\circ} \mathrm{C}$. In these tests, the sample loop containing the photodegraded Imazalil (10 mg L $\left.{ }^{-1}\right)$ and the carrier stream reactor merged on a water bath at different temperatures. The oxidant stream was not heated due to the lack of stability of the oxidant reagent at high temperatures.

The $\mathrm{CL}$ signal increased to $60^{\circ} \mathrm{C}$ and remained stable over this temperature. So this was the selected temperature in the water bath.

\subsubsection{Flow rate}

In order to improve the sensitivity of the FI-CL system, the flow rate of the Imazalil photodegradation and the flow rate of the oxidation reaction were evaluated separately.

In the photodegradation step, sample and buffer flowed separately in a 1:1 proportion and merged to cross the lamp at total flow rates between 2 and $5 \mathrm{~mL}$ $\min ^{-1}$. It was found that the chemiluminescence emission was greater at lower photodegradation velocities (Figure 2). This was because the longer the Imazalil remained in the photoreactor, the greater photofragments were formed. Hence, $2 \mathrm{~mL} \min ^{-1}$ was selected as the optimum flow rate for the photodegradation reaction. Lower velocities were not tested in order not to extend the measurement process. 


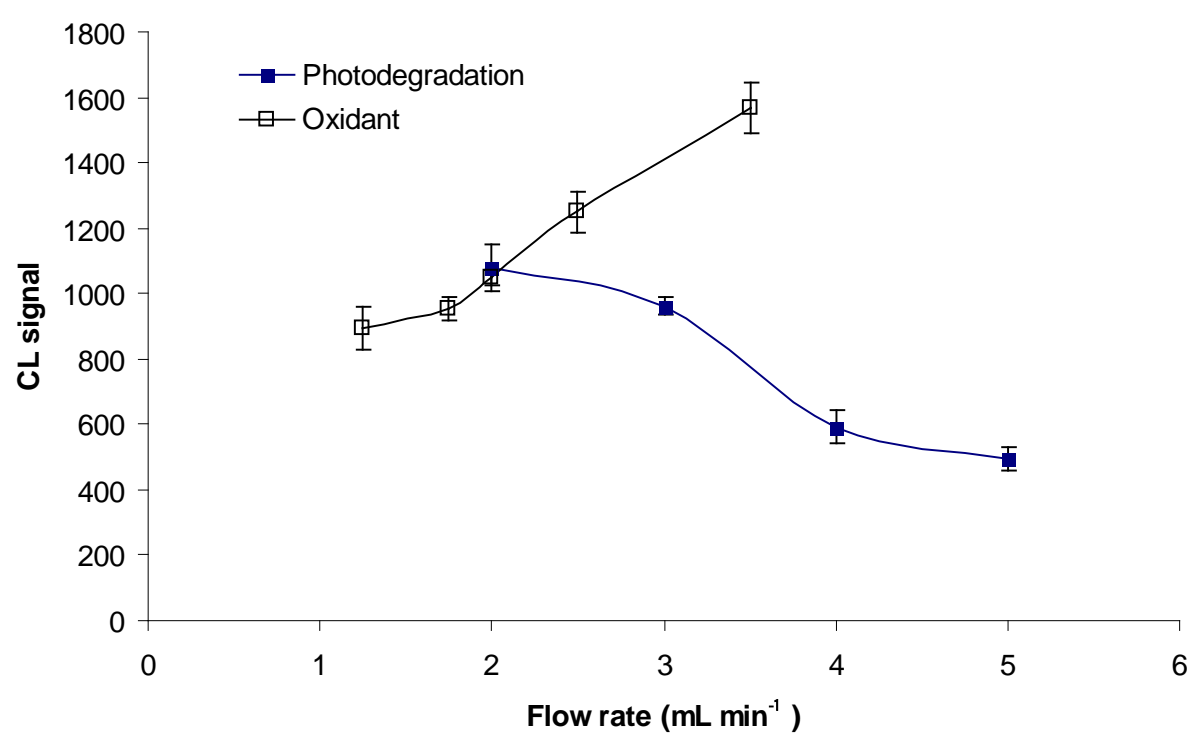

Figure 2. Variation of the chemiluminescence signal in terms of the flow rate (10 $\mathrm{mg} \mathrm{L}^{-1}$ Imazalil standard). V Variable flow rate for the photodegradation step and fixed flow rate for the oxidation $(1.25 \mathrm{~mL}$ $\left.\min ^{-1}\right)$. $\square$ Variable flow rate for the oxidation step and fixed flow rate for the photodegradation $\left(3 \mathrm{~mL} \mathrm{~min}^{-1}\right)$.

The flow rate of the oxidation reaction was evaluated by varying simultaneously the flow rates of the carrier and the oxidant, which flowed in a proportion of 3:1. The flow rate was tested between 1.25 and $3.5 \mathrm{~mL} \mathrm{~min}^{-1}$ for the oxidant, and

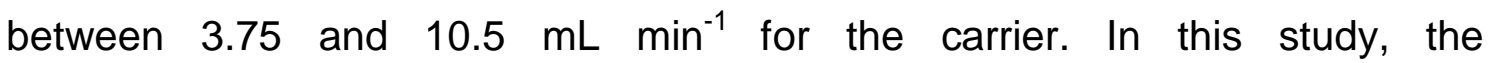
chemiluminescence signal always enhanced on increasing the flow rate (Figure 2) since the chemiluminescence reaction was very fast. However, when working at the highest tested velocity, an excess of pressure appeared in the flow system. Thus optimal flow rates of $2.5 \mathrm{~mL} \mathrm{~min}^{-1}$ for the oxidant and $7.5 \mathrm{~mL} \mathrm{~min}^{-1}$ for the carrier were selected.

\subsubsection{Sample loop}

The sample loop was varied between 350-1500 $\mu \mathrm{L}$. The chemiluminescence signal increased up to $950 \mu \mathrm{L}$ of sample volume and then remained constant. Therefore, this was the selected sample loop. 


\subsubsection{Re-optimization}

To complete the optimization, some parameters that significantly improved the chemiluminescence signal were reoptimized.

The optimum FIA set-up is the one shown in Figure 1. In it, the sample and the buffer flow along the same channel. The sample:buffer ratio was established at 98:2 being $0.01 \mathrm{M}$ the final buffer concentration. With these changes, the flow rate of the photodegradation step was decreased to $1 \mathrm{~mL} \mathrm{~min}^{-1}$, enhancing the $\mathrm{CL}$ signal in a factor of 2.5 .

Finally, the concentration of sodium hydroxide in the oxidation system $(0.5 \mathrm{mM}$ ferricyanide) was optimized with the optimal FIA set-up. The concentration of sodium hydroxide was ranged from $0.1 \mathrm{M}$ to $2 \mathrm{M}$. The chemiluminescence signal increased as the sodium hydroxide concentration increased up to $1.25 \mathrm{M}$, and then remained stable. So, 1.25M sodium hydroxide was selected.

\subsection{Method validation}

\subsubsection{Analytical performance}

The chemiluminescence signal (S) can generally be described as a function of the analyte concentration (C) [11]. In our case, a linear representation was obtained for the plot of the logarithm of the chemiluminescence signal (log $S$ ) as a function of the logarithm of Imazalil concentration $(\log C)$.

Table 1 summarizes the figures of merit for double logarithmic calibration curves obtained when working under different conditions: Imazalil standards prepared without applying SPE in absence of ethanol (Condition 1), standards prepared without SPE in 20\% ethanol (Condition 2), and standards prepared applying SPE at different volumes (Conditions 3-7).

In Condition 2, 40\% of the signal was lost in relation to the standards prepared in Condition 1. On the other hand, slopes of conditions 3 to 7 were compared to the slope of condition 2 by t-test. The results showed that all the calibration curves obtained with SPE (Conditions 3 to 7) were statistically similar to that obtained without SPE in ethanol (Condition 2): calculated t-values were 1.50, $0.85,0.46,0.074$ and 0.59 for Conditions 3 to 7 respectively, and tabulated tvalue was 2.14 at a $95 \%$ confidence level. This supposes a pre-concentration factor of 50 without losses in the Imazalil response. Besides, the calibration 
curve prepared using standards without SPE can be used to determine the Imazalil contents in real samples that do require the application of SPE.

Table 1. Figures of merit for double logarithmic calibration curves obtained in different working conditions

\begin{tabular}{|c|c|c|c|c|}
\hline Conditions & $\begin{array}{c}\text { Calibration curve } \\
\log S=\left(a \pm s_{a}\right)+\left(b \pm s_{b}\right) \cdot \log C \\
\left(r^{2}, n, s_{y / x}\right)\end{array}$ & $\begin{array}{c}\mathrm{LI} \\
\left(\mathrm{mg} \mathrm{L}^{-1}\right)\end{array}$ & $\begin{array}{c}\mathrm{DL} \\
\left(\mathrm{mg} \mathrm{L}^{-1}\right)\end{array}$ & $\begin{array}{c}\mathrm{QL} \\
\left(\mathrm{mg} \mathrm{L}^{-1}\right)\end{array}$ \\
\hline $\begin{array}{l}\text { (1) Without SPE without } \\
\text { ethanol }\end{array}$ & $\begin{array}{c}\log S=(2.610 \pm 0.014)+(1.39 \pm 0.03) \cdot \log C \\
(0.9961,9,0.03)\end{array}$ & $0.75-5$ & 0.115 & 0.273 \\
\hline $\begin{array}{l}\text { (2) Without SPE with } 20 \% \\
\text { ethanol }\end{array}$ & $\begin{array}{c}\log S=(2.528 \pm 0.013)+(1.18 \pm 0.03) \cdot \log C \\
(0.9965,8,0.02)\end{array}$ & $0.75-5$ & 0.171 & 0.480 \\
\hline (3) SPE $10 \mathrm{~mL}$ standard & $\begin{array}{c}\log S=(2.475 \pm 0.010)+(1.30 \pm 0.02) \cdot \log C \\
(0.9980,8,0.02)\end{array}$ & $0.75-5$ & 0.196 & 0.527 \\
\hline (4) SPE $50 \mathrm{~mL}$ standard & $\begin{array}{c}\log S=(3.301 \pm 0.015)+(1.10 \pm 0.03) \cdot \log C \\
(0.9971,6,0.019)\end{array}$ & $0.15-1$ & 0.037 & 0.112 \\
\hline (5) SPE $100 \mathrm{~mL}$ standard & $\begin{array}{c}\log S=(3.75 \pm 0.03)+(1.22 \pm 0.03) \cdot \log C \\
(0.9952,8,0.03)\end{array}$ & $0.075-0.5$ & 0.011 & 0.029 \\
\hline (6) SPE $250 \mathrm{~mL}$ standard & $\begin{array}{c}\log S=(4.17 \pm 0.10)+(1.19 \pm 0.09) \cdot \log C \\
(0.9776,6,0.06)\end{array}$ & $0.03-0.2$ & 0.006 & 0.017 \\
\hline (7) SPE $500 \mathrm{~mL}$ standard & $\begin{array}{c}\log S=(4.58 \pm 0.09)+(1.25 \pm 0.06) \cdot \log C \\
(0.9918,6,0.04)\end{array}$ & $0.015-0.1$ & 0.0034 & 0.009 \\
\hline
\end{tabular}

${ }^{\mathrm{L}}$ Linear Interval; ${ }^{\mathrm{LL}}$ Detection Limit; ${ }^{\mathrm{QL}}$ Quantification Limit

As can be seen in Table 1, working in Condition 7 (standard volumes of 500 $\mathrm{mL}$ ), it was reached a linear dynamic range between $15-100 \mu \mathrm{g} \mathrm{L}^{-1}$ with a detection limit of $3.4 \mu \mathrm{g} \mathrm{L}^{-1}$.

The detection limit was calculated as the concentration corresponding to 3 times the standard deviation of the blank signal $(n=3)$ in all cases. Moreover, it was demonstrated that the experimental detection limits were in accordance with the calculated detection limits by processing standards of $0.2 \mathrm{mg} \mathrm{L}^{-1}$ (SPE $10 \mathrm{~mL}$ ) and $6 \mu \mathrm{g} \mathrm{L}^{-1}$ of Imazalil (SPE $250 \mathrm{~mL}$ ).

The precision of the method was evaluated by repeatability (intraday-precision) and reproducibility (interday-precision) studies at different concentration levels of Imazalil. The percentages of variation coefficients are shown in Table 2. In all cases, the coefficient of variation was below $9.9 \%$.

The sample throughput after solid phase extraction procedure was 12 samples hour $^{-1}$. 
Table 2. Intra-day and inter-day precision studies in different working conditions

\begin{tabular}{|c|c|c|c|}
\hline Conditions & $\begin{array}{c}\text { Imazalil } \\
\text { concentration } \\
\left(\mathrm{mg} \mathrm{L}^{-1}\right)\end{array}$ & $\begin{array}{l}\text { Repeatability } \\
\quad \% C V, n=3\end{array}$ & $\begin{array}{l}\text { Reproducibility } \\
\% \mathrm{CV}, \mathrm{n}\end{array}$ \\
\hline \multirow{2}{*}{$\begin{array}{l}\text { Without SPE without } \\
\text { ethanol }\end{array}$} & 0.75 & $9.9 \%$ & $2.9 \%, 3\left(5 \mathrm{mg} \mathrm{L}^{-1}\right.$ \\
\hline & 3 & $2.1 \%$ & Imazalil) \\
\hline \multirow{4}{*}{$\begin{array}{l}\text { Without SPE with } 20 \% \\
\text { ethanol }\end{array}$} & 0.75 & $9.2 \%$ & $3.0 \%, 8$ \\
\hline & 1.5 & - & $4.0 \%, 11$ \\
\hline & 3 & $4.2 \%$ & $3.8 \%, 3$ \\
\hline & 4 & - & $2.9 \%, 3$ \\
\hline \multirow{2}{*}{ SPE $10 \mathrm{~mL}$ standard } & 0.75 & $2.4 \%$ & 7.95\%, 3 (5 $\mathrm{mg} \mathrm{L}^{-1}$ \\
\hline & 3 & $5.9 \%$ & Imazalil) \\
\hline SPE $50 \mathrm{~mL}$ standard & 0.3 & $3.0 \%$ & - \\
\hline SPE $100 \mathrm{~mL}$ standard & 0.3 & $2.5 \%$ & - \\
\hline \multirow{4}{*}{ SPE $250 \mathrm{~mL}$ standard } & 0.03 & - & $5.1 \%, 4$ \\
\hline & 0.06 & $6.4 \%$ & $4.5 \%, 4$ \\
\hline & 0.09 & - & $6.0 \%, 3$ \\
\hline & 0.16 & - & $1.6 \%, 3$ \\
\hline SPE $500 \mathrm{~mL}$ standard & 0.03 & $7.8 \%$ & $\begin{array}{c}6.9 \%, 3 \text { (0.1 } \mathrm{mg} \mathrm{L}^{-1} \\
\text { Imazalil) }\end{array}$ \\
\hline
\end{tabular}

\subsubsection{Interference study}

In order to evaluate the possible interference of the most common anions and cations present in water $\left(\mathrm{CH}_{3} \mathrm{COO}, \mathrm{Cl}^{-}, \mathrm{CO}_{3}^{2-}, \mathrm{CrO}_{4}^{2-}, \mathrm{H}_{2} \mathrm{PO}_{4}^{-}, \mathrm{NO}_{2}^{-}, \mathrm{NO}_{3}^{-}, \mathrm{SO}_{4}^{2-}, \mathrm{r}^{-}\right.$, $\mathrm{Ca}^{2+}, \mathrm{Cd}^{2+}, \mathrm{Co}^{2+}, \mathrm{Cr}^{3+}, \mathrm{Cu}^{2+}, \mathrm{Fe}^{3+}, \mathrm{Mg}^{2+}, \mathrm{Mn}^{2+}, \mathrm{NH}_{4}^{+}, \mathrm{Ni}^{2+}, \mathrm{Pb}^{2+}$ and $\left.\mathrm{Zn}^{2+}\right)$, Imazalil standards $\left(0.06 \mathrm{mg} \mathrm{L}^{-1}\right)$ in presence of each one of the ions under study were prepared. SPE was applied to $250 \mathrm{~mL}$ of that solutions and the signal was compared with the Imazalil standard $\left(0.06 \mathrm{mg} \mathrm{L}^{-1}\right)$ signal in the absence of interfering ions. Table 3 shows the percentage of relative error $\left(\% \mathrm{E}_{r}\right)$ and the maximum concentrations allowed for each one of the tested interfering ions. It was considered that there was no interference when the percentage of relative error of the signal was inferior to $10 \%$ because the previous precision studies always gave coefficients of variation below 9.9\% (Table 2). As Table 3 shows, none of the tested ions interfere at concentrations usually found in water samples.

Moreover, the interference of some conazole or benzimidazole fungicides (such as imidazolidinethione, myclobutanyl, thiabendazole and triflumizole) was 
studied. Table 3 summarizes the maximum concentration levels allowed and the percentage of relative error in the Imazalil signal. As can be seen, imidazolidinethione, myclobutanyl and thiabendazole did not interfere at concentrations like the MRL established by the Regulations of the Hydraulic Public Domain for pesticide dumping. Only triflumizole slightly interfered at 0.05 $\mathrm{mg} \mathrm{L}^{-1}$, but its inteference dissapeared at a concentration of $0.025 \mathrm{mg} \mathrm{L}^{-1}$. Therefore, a false positive could be given at higher triflumizole concentrations. In these conditions, the proposed method wouldn't be ruled out as it could still be applied as a screening procedure.

Table 3. Study of potential interferents: Maximum allowed concentrations and percentages of relative error.

\begin{tabular}{|c|c|c|}
\hline Interferent & $\begin{array}{l}\text { Maximum allowed } \\
\text { concentration }\end{array}$ & $\begin{array}{c}\text { \%Relative error } \\
\left(\% \mathrm{E}_{\mathrm{r}}\right)\end{array}$ \\
\hline $\mathrm{Ca}^{2+}$ & $250 \mathrm{mg} / \mathrm{L}$ & 6.7 \\
\hline $\mathrm{Cd}^{2+}$ & $10 \mathrm{mg} / \mathrm{L}$ & -0.2 \\
\hline $\mathrm{Co}^{2+}$ & $1 \mathrm{mg} / \mathrm{L}$ & -0.5 \\
\hline $\mathrm{Cr}^{3+}$ & $10 \mathrm{mg} / \mathrm{L}$ & 2.5 \\
\hline $\mathrm{Cu}^{2+}$ & $10 \mathrm{mg} / \mathrm{L}$ & 7.6 \\
\hline $\mathrm{Fe}^{3+}+\mathrm{Zn}^{2+}$ & $100 \mathrm{mg} / \mathrm{L}+10 \mathrm{mg} / \mathrm{L}$ & -2.6 \\
\hline $\mathrm{Mg}^{2+}$ & $200 \mathrm{mg} / \mathrm{L}$ & -8.0 \\
\hline $\mathrm{Mn}^{2+}$ & $1 \mathrm{mg} / \mathrm{L}$ & 1.2 \\
\hline $\mathrm{NH}_{4}^{+}$ & $10 \mathrm{mg} / \mathrm{L}$ & -1.9 \\
\hline $\begin{array}{l}\mathrm{Ni}^{2+} \\
\mathrm{Pb}^{2+}\end{array}$ & $\begin{array}{l}10 \mathrm{mg} / \mathrm{L} \\
1 \mathrm{mg} / \mathrm{L}\end{array}$ & $\begin{array}{l}-0.4 \\
-2.0\end{array}$ \\
\hline $\mathrm{CrO}_{4}^{2-}$ & $1 \mathrm{mg} / \mathrm{L}$ & -1.8 \\
\hline $\mathrm{Cl}^{-}+\mathrm{I}^{-}$ & $250 \mathrm{mg} / \mathrm{L}+50 \mathrm{mg} / \mathrm{L}$ & 7.3 \\
\hline $\mathrm{CH}_{3} \mathrm{COO}^{-}$ & $100 \mathrm{mg} / \mathrm{L}$ & 2.5 \\
\hline $\mathrm{CO}_{3}^{2-}$ & $500 \mathrm{mg} / \mathrm{L}$ & -9.4 \\
\hline $\mathrm{H}_{2} \mathrm{PO}_{4}^{-}$ & $50 \mathrm{mg} / \mathrm{L}$ & -7.9 \\
\hline $\mathrm{NO}_{3}^{-}+\mathrm{NO}_{2}^{-}$ & $100 \mathrm{mg} / \mathrm{L}+50 \mathrm{mg} / \mathrm{L}$ & 8.5 \\
\hline $\mathrm{SO}_{4}^{2-}$ & $250 \mathrm{mg} / \mathrm{L}$ & -4.3 \\
\hline Imidazoledinethione & $50 \mu \mathrm{g} / \mathrm{L}$ & 2.1 \\
\hline Myclobutanil & $50 \mu \mathrm{g} / \mathrm{L}$ & -1.7 \\
\hline Thiabendazole & $50 \mu \mathrm{g} / \mathrm{L}$ & 2.8 \\
\hline Triflumizole & $25 \mu \mathrm{g} / \mathrm{L}$ & 4.3 \\
\hline
\end{tabular}




\subsection{Application}

The explained method was validated by spiking real water samples. $250 \mathrm{~mL}$ of samples fortified with variable concentrations of Imazalil were pre-concentrated and cleaned by means of the SPE procedure. Later, they were introduced into the FI-CL system. The percentages of recovery of added Imazalil for each fortified sample are shown in Table 4. As can be seen, S1, S5, S7 and S8 were fortified in triplicate at one level of concentration, and S2, S3, S4 and S6 were fortified at four levels of concentration. The recoveries were between 95.7 and $110 \%$ in all samples, thus the accuracy of the method was demonstrated.

FIA-grams obtained by processing $250 \mathrm{~mL}$ of: a blank, a standard of $0.06 \mathrm{mg} \mathrm{L}^{-1}$ Imazalil, tap water sample $1\left(\mathrm{~S} 1\right.$ ) and S1 fortified with $0.06 \mathrm{mg} \mathrm{L}^{-1}$ Imazalil (S1F), are shown in Figure 3.

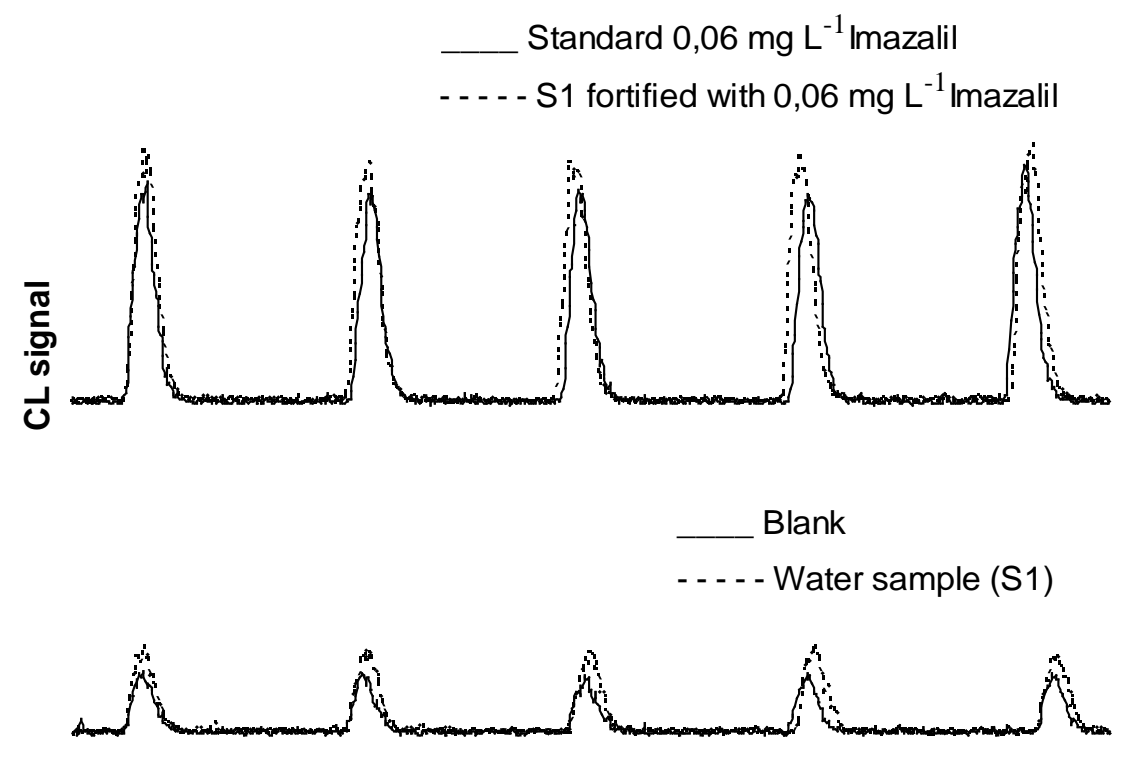

Figure 3. FIA-gram obtained for a blank, an Imazalil standard of $60 \mu \mathrm{g} \mathrm{L}^{-1}$, tap water sample (S1), and tap water sample 1 fortified with $60 \mu \mathrm{g} \mathrm{L}^{-1}$ of Imazalil (S1F). Sample or standard processed volume: $250 \mathrm{~mL}$. 
Table 4. Recoveries obtained for real water samples fortified at different concentration levels of Imazalil.

\begin{tabular}{cccc}
\hline Sample & $\begin{array}{c}\text { Added Imazalil } \\
\text { concentration } \\
\left(\mathbf{m g ~ L}^{-1}\right)\end{array}$ & $\begin{array}{c}\text { Found Imazalil } \\
\text { concentration } \\
\left(\mathbf{m g ~ L}^{-1}\right)\end{array}$ & $\begin{array}{c}\text { \%Recovery } \\
\text { (\%Rec } \pm \mathbf{~ s ) , ~} \mathbf{n}\end{array}$ \\
\hline S1 & 0.06 & $(0.0579 \pm 0.0006)$ & $(95.7 \pm 1.0), 3$ \\
\hline & 0.03 & 0.02909 & \\
S2 & 0.06 & 0.06102 & $(100 \pm 2), 4$ \\
& 0.09 & 0.08948 & \\
\hline & 0.16 & 0.1617 & \\
S3 & 0.03 & 0.03363 & \\
& 0.06 & 0.06808 & $(108 \pm 7), 4$ \\
& 0.09 & 0.09849 & \\
& 0.16 & 0.15581 & \\
S4 & 0.03 & 0.03120 & \\
& 0.06 & 0.06327 & $(101 \pm 5), 4$ \\
& 0.09 & 0.08928 & \\
\hline S5 & 0.16 & 0.15045 & $(110 \pm 9), 3$ \\
\hline & 0.06 & $(0.066 \pm 0.005)$ & \\
S6 & 0.03 & 0.03082 & \\
& 0.06 & 0.05585 & $(96 \pm 5), 4$ \\
& 0.09 & 0.08733 & \\
\hline S7 & 0.16 & 0.14871 & \\
\hline S8 & 0.06 & $(0.058 \pm 0.004)$ & $(96 \pm 6), 3$ \\
\hline
\end{tabular}

\section{Conclusions}

The chemiluminescence method proposed allows the determination of Imazalil in water samples in a new, fast, economic and simple way. This is the first time that a chemiluminescence method for the determination of this fungicide has been proposed. The method has proved to be precise, selective and sensitive, reaching a detection limit of $3.4 \mathrm{ng} \mathrm{mL}^{-1}$ by preconcentrating $500 \mathrm{~mL}$ of the Imazalil solution with C18 SPE cartridges. This detection limit is below the maximum concentration level established by the Regulations of the Hydraulic Public Domain for pesticide dumping. The sample throughput is 12 samples hour $^{-1}$ and no interference of the most commonly ions present in water samples was observed. The method has been satisfactorily applied to the analysis of environmental water samples from different sources obtaining recoveries for added Imazalil around 100\%. 


\section{Acknowledgements}

The authors are grateful to The Spanish Ministry of Education and Science and FEDER funds for finnantial support: Project CTM2006-11991. The translation of this paper was funded by the Universidad Politécnica de Valencia, Spain.

\section{References}

[1] Council Directive 98/83/EC of 3 November 1998 on the quality of water intended for human consumption.

[2] RD 849/1986 of 11 april of the Regulations of the Hydraulic Public Domain

[3] Picó Y., la Farré M., Soler C., Barceló D. (2007) J Chromatogr A 1176 1-2: 123-134.

[4] Ibáñez M., Sancho J.V., Hernández F., McMillan D., Rao R. (2008) Trends Analyt Chem 27 5: 481-489.

[5] Yoshioka N., Akiyama Y., Teranishi K. (2004) J Chromatogr A 1022 1-2: 145-150.

[6] Watanabe E., Yoshimura Y., Yuasa Y., Nakazawa H. (2001) Anal Chim Acta 433 2: 199-206.

[7] Ito Y., Ikai Y., Oka H., Hayakawa J., Kagami T. (1998) J Chromatogr A 810 1-2: 81-87.

[8] Garrido J., de Alba M., Jimenez I., Casado E., Folgueiras M.L. (1997) J Chromatogr A 765 1: 91-97.

[9] Charlton A.J.A., Jones A. (2007) J Chromatogr A 1141 1: 117-122.

[10] Rodríguez R., Picó Y., Font G., Mañes J. (2001) J Chromatogr A 924 1-2: 387-396.

[11] Balinova A. (1995) Anal Chim Acta 311 3: 423-427.

[12] Menezes Filho A., Neves dos Santos F., Afonso de Pereira P. (2010) Mikrochemical Journal 96 139-145.

[13] Beale D.J., Porter N.A., Roddick F.A. (2009) Talanta 78 2: 342-347.

[14] Albert-García J.R., Martínez-Calatayud J. (2008) Talanta 75 3: 717-724.

[15] Meseguer-Lloret S., Campíns-Falcó P., Tortajada-Genaro L.A., BlascoGómez F. (2003) Int J Environ Anal Chem 83 5: 405 - 416. 
[16] Moliner-Martínez Y., Meseguer-Lloret S., Tortajada-Genaro L.A., CampínsFalcó P. (2003) Talanta 60 2-3: 257-268.

[17] Lin Q., Guiraúm A., Escobar R., de la Rosa F. (1993) Anal Chim Acta 283 1: 379-385

[18] Townshend A., Ruengsitagoon W., Thongpoon C., Liawruangrath S. (2005) Anal Chim Acta 541: 105-111.

[19] Lattanzio G., García-Campaña A.M., Soto-Chinchilla J.J., Gámiz-Gracia L., Girotti S. (2008) J Pharm Biomed Anal 462 381-385.

[20] Catalá Icardo M., García Mateo J.V., Fernández Lozano M., Martínez Calatayud J. (2003) Anal Chim Acta 499 1-2: 57-69.

[21] Ciborowski M., Catalá Icardo M., García Mateo J.V., Martínez Calatayud J. (2004) J Pharm Biomed Anal 36 4: 693-700.

[22] Yang X.F., Li H. (2004) Talanta 64 2: 478-483.

[23] Gómez-Taylor B., Palomeque M., García Mateo J.V., Martínez Calatayud J. (2006) J Pharm Biomed Anal 41 2: 347-357.

[24] López Paz J.L., Catalá-Icardo M. (2008) Anal Chim Acta 625 2: 173-179.

[25] López Malo D., Martínez Calatayud J. (2008) Talanta 77 2: 561-565. 